\title{
Shear and Longitudinal Modulus of Elasticity in Structural Lumber Beams
}

\author{
André Luis Christoforo ${ }^{1, *}$, Tulio Hallak Panzera ${ }^{2}$, Diogo Aparecido Lopes Silva ${ }^{3}$, \\ Juliano Fiorelli ${ }^{4}$, Francisco Antonio Rocco Lahr ${ }^{5}$
}

\begin{abstract}
${ }^{1}$ Department of Civil Engineering, Federal University of São Carlos, São Carlos, 13565-905, Brazil ${ }^{2}$ Department of Mechanical Engineering, Federal University of São João del-Rei, São João del-Rei, 36307-352, Brazil ${ }^{3}$ Department of Production Engineering, Engineering School of São Carlos (EESC/USP), São Carlos, 13566-590, Brazil ${ }^{4}$ Department of Biosystems Engineering, São Paulo State University (FZEA/USP), Pirassununga, 13635-900, Brazil ${ }^{5}$ Department of Structural Engineering, Engineering School of São Carlos (EESC/USP), São Carlos, 13566-590, Brazil
\end{abstract}

\begin{abstract}
This study aimed to present, with the aid of the four points static bending, conducted nondestructively, analytical methodology to determine the longitudinal $(E)$ and shear modulus $(G)$ of elasticity in lumber beams. The woods used were Manilkara spp and Pinus elliottii. Were used three different values to the form factor coefficient of the rectangular cross section, allowing evaluating the differences between the shear stiffness values obtained by wood species. The results of the analysis of variance indicated statistical equivalence between shear modulus of elasticity for the two wood species investigated, unless revealing significant the influence of the form factors used to determine the shear modulus of elasticity. The coefficients of the relationship between the modulus of elasticity $(E=\lambda \cdot G)$ obtained from the least squares method were equal to 37 and 33 to the woods Manilkara spp and Pinus elliottii, be revealing $85 \%$ and $65 \%$ higher respectively then the relationship $\left(E=20^{\circ} G\right)$ presented in the Brazilian standard ABNT NBR 7190. It is emphasized that these results may be different for the same or different wood species, justifying the use of this methodology in each work developed.
\end{abstract}

Keywords Lumber, Beams theory, Shear and longitudinal modulus of elasticity

\section{Introduction}

Among the fundamentals properties required for the design of a structure highlights the modulus of elasticity. In the case of wood, because it is a natural material of great complexity and anatomical variability, with three axes of symmetry in the radial, tangential and longitudinal, obtaining all their elastic parameters is compromised[1]. However, structural designs are made with possess of their equivalents mechanical properties, resulting from experimental tests standardized by regulatory codes aimed at quantifying these variables due to mechanical stress conditions.

In a project of beams, as well as other structural elements, knowledge of the longitudinal (E) and shear (G) modulus of elasticity is of fundamental importance[2]. In Brazil, the characterization of wood in bending is done according to the Brazilian standard ABNT NBR 7190[3] (Design of Wooden Structures), which use of the three points static bending, restricted to small samples and free from defects, having an empirical relationship for obtaining the shear modulus

* Corresponding author:

alchristoforo@yahoo.com.br (André Luis Christoforo)

Published online at http://journal.sapub.org/ijme

Copyright (C) 2014 Scientific \& Academic Publishing. All Rights Reserved known the value of the longitudinal modulus, being $G=E / 20$.

In Brazil, researches involving the characterization of pieces of wood with structural dimensions follow the assumptions and calculation methods contained in international standards, which may be mentioned the works of Pigozzo et al.[4], Fiorelli et al.[5] and Miotto and Dias[6].

Nondestructive testing methods have been widely used to obtain the longitudinal elastic modulus in wooden beams, emphasizing the use of ultrasound and transverse vibration, emphasizing simplicity and efficiency of the use of such methodologies, justified by the possibility of use the peace after tested[7-14].

With respect to the determination of the shear modulus of elasticity in wooden beams as in specimens of small dimensions is little research developed among them, highlighting the work of Rocco Lahr[15], Burdzik and Nkwera[16], Zangiácomo and Rocco Lahr[17] and Christoforo et al.[18].

Rocco Lahr[15] evaluated, among others[16, 17], the influence of the dimensions of the specimens of lumber for which the effect of shear forces becomes negligible in the calculation of displacements, reaching the ratio $L / h \geq 21$, where $L$ is the useful length and $h$ is the height of the cross section of the specimen.

Christoforo et al.[18] developed, with the aid of the three-points static bending, conducted nondestructively, 
analytical methodology to determine the longitudinal (E) and the shear modulus $(\mathrm{G})$ of elasticity in round timber beams, using Eucalyptus wood clone. They used three different values to the form factor coefficient of the circular cross section, allowing evaluating the differences between the shear stiffness values obtained. The results indicated no statistical equivalence between the shear modulus of elasticity, revealing be significant the influence of the form factors used to determine the shear modulus of elasticity. The coefficient $(\lambda)$ of the relationship between the modulus of elasticity $(E=\lambda \cdot G)$ obtained from the least squares method were equal to 118 , revealing 5.9 higher than the relationship $(E=20 \cdot G)$ presented in the Brazilian standard ABNT NBR 7190:1997. It is emphasized that these results may be different for the same or different wood species, justifying the use of this methodology in each research developed.

Christoforo et al.[19] presented an analytical method to calculate the longitudinal and shear modulus of structural lumber, using the three points static bending. The wood used in the experiments were Pinus elliottii and Corymbia citriodora. The equations for the calculation of the elastic moduli were developed by the least squares method, and the shape of the shear coefficient for rectangular cross section was adopted as 0.666 . The results of the coefficients between the longitudinal and shear modulus of elasticity for the woods Pinus elliottii and Corymbia citriodora were equal to 18.70 and 21.20 , being proximate to the coefficient (20) established by the Brazilian standard ABNT NBR 7190[3].

This paper, based on the work of Christoforo et al.[18] and Christoforo et al.[19], aimed to present, with the aid of the theory of Timoshenko beams, an analytical methodology for obtaining the longitudinal and shear modulus of elasticity in structural lumber beams, with the aid of the least squares method and the four points static bending, also investigating the influence of the form factor in the calculation of the shear modulus of elasticity.

\section{Materials and Methods}

The experimental methodology developed for calculate the modulus of elasticity E and $G$ of structural lumber was based on work from Rocco Lahr[15], as also done in the work of Christoforo et al.[18]. The modulus of elasticity was obtained from geometric and linearity condition, with the largest displacement in the experiments was limited to $\mathrm{L} / 200$, measurement of small displacements defined by Brazilian standard[3].

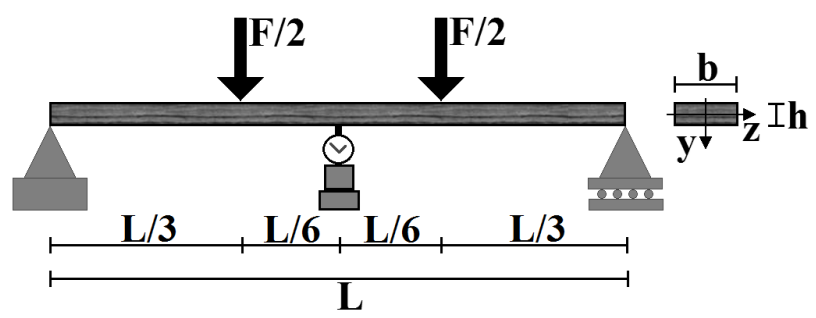

Figure 1. Four points static bending
The Virtual Force Method (VFM) was employed on the structural model of the four-point bending (Figure 1), aiming to find an expression for the calculation of the displacement at the midpoint of the beam $(\delta)$, considering the bending moment and shear efforts. Note that the four points static bending static bending is adopted by American Standard ASTM D-198[20] to determine the modulus of elasticity in bending.

Generally, when considering only bending and shearing efforts, the displacement on a point of interest to a structure consisting of bar elements is obtained by Equation 1 (MFV), wherein:

$$
1 \cdot \delta=\sum_{i=1}^{n}\left(\int_{\Omega_{i}} \frac{M(x) \cdot m(x)}{E \cdot I} d x+\int_{\Omega_{i}} \frac{f_{S} \cdot Q(x) \cdot q(x)}{G \cdot A} d x\right)
$$

$\delta$ - Linear displacement or rotation to be calculated by the use of force or virtual moment;

$M(x)$ - variation of bending moment for a slice of the structure according to the actual load history;

$m(x)$ - variation of bending moment for a slice of the structure according to the employment of a force or unit moment applied at a point of interest;

$Q(x)$ - variation of shear for a slice of the structure according to the actual load history;

$q(x)$ - variation of shear for a slice of the structure according to the employment of a force or unit moment applied at a point of interest;

$f_{s}$ - form factor of the cross section (depending on the geometry of the cross section);

$\Omega$ - domain of integration;

$E$ - longitudinal modulus of elasticity or Young's modulus;

$I$ - moment of inertia of the cross section;

$G$ - shear modulus of elasticity;

$A$ - cross-sectional area;

$L$ - length of the beam.

Using Equation 1 in the structural model adapted to the four points static bending (Figure 1), the displacement at the midpoint is expressed by Equation 2, where $b$ and $h$ are respectively the width and height of rectangular cross-section of the beam.

$$
\delta=\frac{23 \cdot F \cdot L^{3}}{108 \cdot E \cdot b \cdot h^{3}}+\frac{F \cdot L \cdot f_{S}}{6 \cdot b \cdot h \cdot G}
$$

According to the present methodology for calculating the moduli of elasticity are necessary the execution of two successive experimental tests on the same element. At first, assuming the $L_{l}$ length of the element, with $L_{l} / h \geq 21$ [15], determines the value of the $F_{l}$ force responsible for causing a shift of $\delta_{I}=L_{I} / 200$. In the second trial bending the supports were approximate, giving a new useful length $\left(L_{2}\right)$, and must respect the inequality $L_{2} / h \geq 5 / 4[21]$, ensuring that the sections remain flat after deformed, obtaining a value of force $\left(F_{2}\right)$ responsible for causing a displacement equal to $\delta_{2}$ $=L_{2} / 200$. 
The employment of $F_{1}$ and $F_{2}$ forces, $L_{1}$ and $L_{2}$ measures and displacements $\delta_{1}$ and $\delta_{2}$ obtained in trials in Equation 2 leads to a system with two equations in two unknowns, whose solution provides the longitudinal and shear modulus of elasticity of structural lumber beams, expressed respectively by Equations 3 and 4 .

$$
\begin{gathered}
E=\frac{23 \cdot L_{1} \cdot L_{2} \cdot F_{1} \cdot F_{2} \cdot\left(L_{2}{ }^{2}-L_{1}{ }^{2}\right)}{108 \cdot b \cdot h^{3} \cdot\left(F_{1} \cdot L_{1} \cdot \delta_{2}-F_{2} \cdot L_{2} \cdot \delta_{1}\right)} \\
G=\frac{f_{S} \cdot L_{1} \cdot L_{2} \cdot F_{1} \cdot F_{2} \cdot\left(L_{1}{ }^{2}-L_{2}{ }^{2}\right)}{6 \cdot b \cdot h \cdot\left(F_{1} \cdot L_{1}{ }^{3} \cdot \delta_{2}-F_{2} \cdot L_{2}{ }^{3} \cdot \delta_{1}\right)}
\end{gathered}
$$

Equations 3 and 4 can be adapted for measurements of displacements $\delta_{1}=L_{1} / 200$ and $\delta_{2}=L_{2} / 200$, as well as expressing equations 5 and 6 .

$$
\begin{aligned}
& E=\frac{1150 \cdot F_{1} \cdot F_{2} \cdot\left(L_{2}^{2}-L_{1}^{2}\right)}{27 \cdot b \cdot h^{3} \cdot\left(F_{1}-F_{2}\right)} \\
& G=\frac{100 \cdot F_{1} \cdot F_{2} \cdot f_{s} \cdot\left(L_{1}^{2}-L_{2}{ }^{2}\right)}{3 \cdot b \cdot h \cdot\left(F_{1} \cdot L_{1}{ }^{2}-F_{2} \cdot L_{2}{ }^{2}\right)}
\end{aligned}
$$

The equations 5 and 6 used in obtaining the modulus of elasticity not take into consideration the own weight of the piece. However, Christoforo et al.[18] proved to be negligible the influence of own weight in the calculation of displacements, validating the methodology here presented.

The proposed methodology was used in wooden beams of the Pinus elliottii and Manilkara spp. (Maçaranduba) species, provided by MJ Wood Company of São Carlos (SP-Brazil), tested in the position of least inertia (flatwise) and positioned in the Longitudinal and Radial plane (LR). For each species of wood were manufactured twelve specimens of dimensions $140 \times 5 \times 3 \mathrm{~cm}$.

The lengths used in bending tests were $L_{I}=130 \mathrm{~cm}$ and $L_{2}=80 \mathrm{~cm}$, obtained from each specimen for each species the values of the forces responsible for causing the displacements of $0.65 \mathrm{~cm}\left(L_{1} / 200\right)$ and $0.40 \mathrm{~cm}\left(L_{2} / 200\right)$.

The form factor $\left(f_{s}\right)$ in the present calculation of shear modulus of elasticity is a constant that depends on the geometry of the cross section of the peace. In literature, for square or rectangular cross section, some authors have different values of form factors. In order to evaluate the influence of employment of the coefficient in order to calculate the shear modulus of elasticity, these were varied, assuming values: $0.667,0.822$ and 0.833 , respectively obtained from the works of Timoshenko[22], Mindlin and Deresiewicz[23] and Roark[24].

To check the influence of the shape coefficient for calculating the shear modulus was used the analysis of variance (ANOVA), with proven assumptions of residuals normality, homogeneity and independence with the normality test of Anderson-Darling, with the residual plots versus fitted values and residuals versus order respectively by response investigated, both with the aid of the software Minitab ${ }^{\circledR}$ version 14 .
In order to relate the values of the elastic moduli $E$ and $G$ for the species evaluated and later compared the relationship defined by the Brazilian standard ABNT NBR 7190[3], has been used the least squares method[18, 25], expressed by Equation $7, \lambda$ is the coefficient to be adjusted to the lesser residue $(E=\lambda \cdot G)$.

$$
f(\alpha)=\frac{1}{2} \cdot \sum_{i=1}^{n}\left(E_{i}-\lambda \cdot G_{i}\right)^{2}
$$

\section{Results}

Tables 1 and 2 shows the mean values $\left(X_{m}\right)$, standard deviations $(S D)$ and coefficients of variation $(C V)$ of the longitudinal and shear modulus of elasticity for the woods Manilkara spp and Pinus elliottii respectively.

Table 1. Modulus of elasticity of Manilkara spp wood species

\begin{tabular}{ccccc} 
& & & & \\
\cline { 3 - 5 }$S p$. & $\mathbf{E}$ & $f_{s}(0,667)$ & $f_{s}(0,822)$ & $f_{s}(0,833)$ \\
\hline 1 & $\mathbf{M P a})$ & $(\mathbf{M P a})$ & $\mathbf{G}$ & $\mathbf{G}$ \\
2 & 19922 & 274 & 337 & 342 \\
$(\mathbf{M P a})$ & 535 \\
3 & 15524 & 428 & 528 & 234 \\
4 & 19121 & 187 & 231 & 368 \\
5 & 20551 & 294 & 363 & 641 \\
6 & 14424 & 513 & 632 & 636 \\
7 & 16767 & 509 & 627 & 376 \\
8 & 15212 & 301 & 371 & 366 \\
9 & 15824 & 293 & 361 & 439 \\
10 & 20356 & 351 & 433 & 607 \\
11 & 17463 & 486 & 599 & 524 \\
12 & 14578 & 419 & 517 & 487 \\
\hline $\boldsymbol{X}_{\boldsymbol{m}}$ & 17504 & 390 & 480 & 463 \\
$\boldsymbol{S D}$ & 17271 & 370 & 457 & 130 \\
$\boldsymbol{C} \boldsymbol{V}(\%)$ & 2253 & 104 & 128 & 28 \\
\hline
\end{tabular}

Table 2. Modulus of elasticity of Pinus elliottii wood species

\begin{tabular}{ccccc} 
& & & & \\
\cline { 3 - 5 }$S p$. & $\mathbf{E}$ & $f_{s}(0,667)$ & $f_{s}(0,822)$ & $f_{s}(0,833)$ \\
\hline 1 & $\mathbf{M P a})$ & $(\mathbf{M P a})$ & $\begin{array}{c}\mathbf{G} \\
(\mathbf{M P a})\end{array}$ & $\begin{array}{c}\mathbf{G} \\
(\mathbf{M P a})\end{array}$ \\
2 & 9099 & 300 & 370 & 375 \\
3 & 11330 & 261 & 321 & 326 \\
4 & 11033 & 131 & 161 & 163 \\
5 & 10680 & 348 & 428 & 434 \\
6 & 13191 & 156 & 192 & 195 \\
7 & 11205 & 351 & 432 & 438 \\
8 & 10940 & 269 & 331 & 336 \\
9 & 9321 & 219 & 270 & 274 \\
10 & 10224 & 138 & 170 & 172 \\
11 & 10429 & 392 & 483 & 490 \\
12 & 9571 & 223 & 275 & 279 \\
\hline $\boldsymbol{X}_{\boldsymbol{m}}$ & 10441 & 263 & 323 & 328 \\
$\boldsymbol{S D}$ & 10622 & 254 & 313 & 318 \\
$\boldsymbol{C} \boldsymbol{V}(\boldsymbol{\%})$ & 1090 & 85 & 105 & 107 \\
\hline & 10 & 34 & 34 & 34 \\
\hline
\end{tabular}

Figures 2 and 3 illustrate the normality plot of Anderson-Darling test for the modulus of elasticity of the 
timbers Manilkara spp and Pinus elliottii respectively, showing normal distributions for all responses by the $\mathrm{P}$-values found are greater than $0.05(5 \%)$.

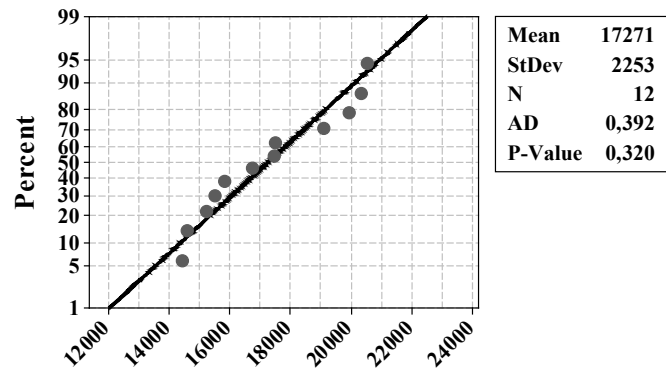

E (MPa)

(a)

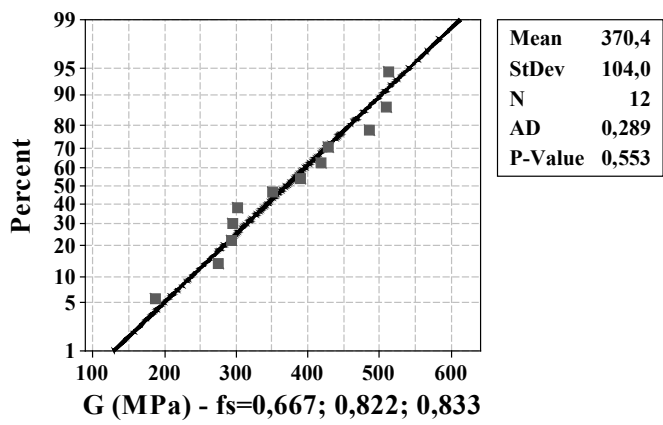

(b)

Figure 2. Normality plot of modulus of elasticity of Manilkara spp wood species

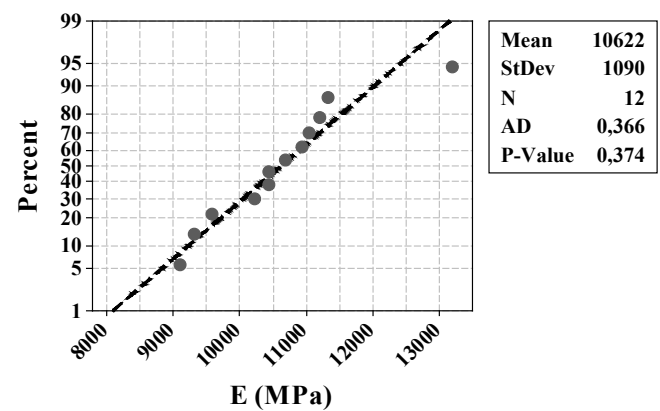

(a)

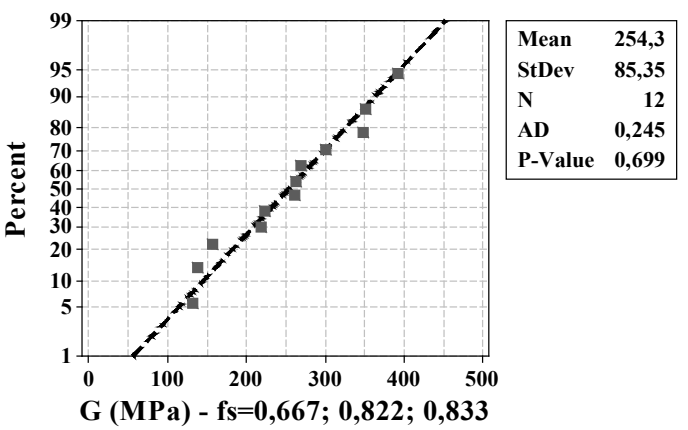

(b)

Figure 3. Normality plot of modulus of elasticity of Pinus elliottii wood species
The P-value of the ANOVA on the influence of form factors in calculating the shear modulus of elasticity was equal to 0.129 , an adjusted coefficient of determination ( $\mathrm{R}^{2}$ (Adj.)) equal to $6.32 \%$. By P-value is greater than 0.05 , it appears to be equivalent the shear modulus of elasticity for Manilkara spp wood species. Figure 4 illustrates the normality plot of the residuals (4a), homogeneity (4b) and independence (4c).

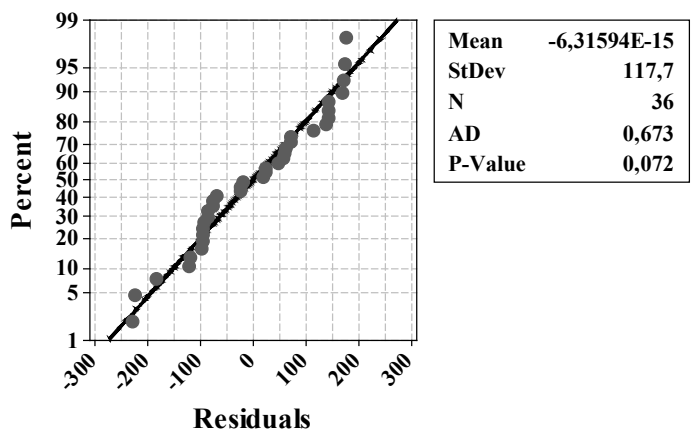

(a)

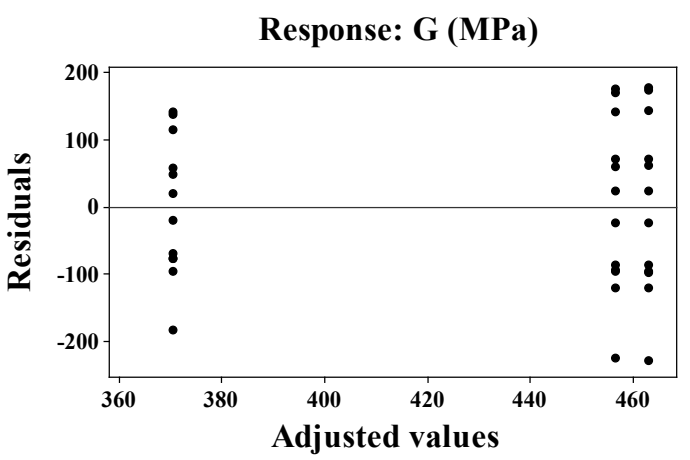

(b)

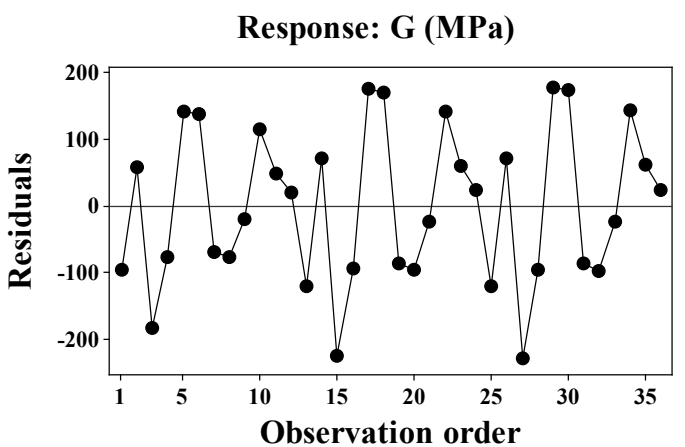

(c)

Figure 4. ANOVA validation of the form factor on the shear modulus of elasticity of Manilkara spp wood species

The P-value of the ANOVA on the influence of form factors in calculating the shear modulus of elasticity was equal to 0.236 , an adjusted coefficient of determination ( $\mathrm{R}^{2}$ (Adj.)) equal to $2.83 \%$. By P-value is greater than 0.05 , it appears to be equivalent the shear modulus of elasticity for Pinus elliottii wood species. Figure 5 illustrates the 
normality plot of the residuals (5a), homogeneity (5b) and independence $(5 \mathrm{c})$.

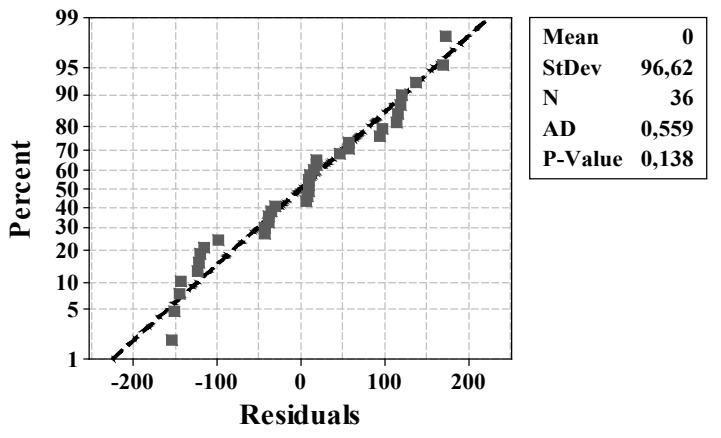

(a)

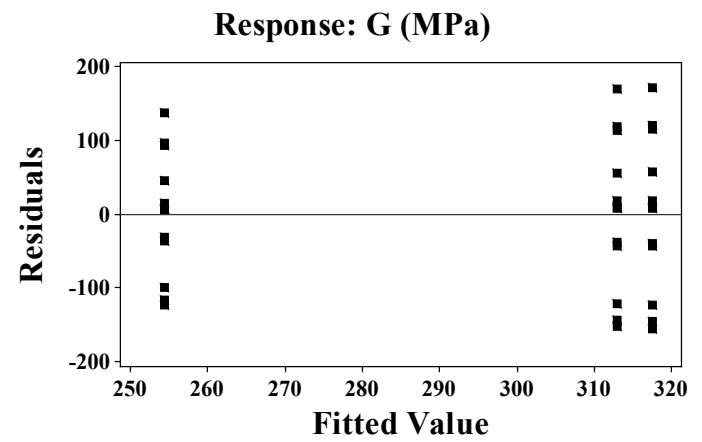

(b)

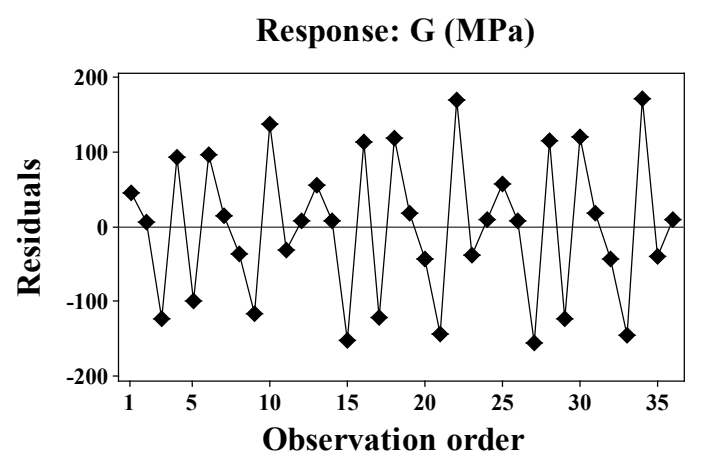

(c)

Figure 5. ANOVA validation of the form factor on the shear modulus of elasticity of Pinus elliottii wood species

Table 3. Ratios between the longitudinal and shear modulus of elasticity for the wood species

\begin{tabular}{cccc}
\cline { 2 - 4 } & \multicolumn{3}{c}{ Manilkara spp } \\
\cline { 2 - 4 } & $E=\lambda \cdot G$ & $\begin{array}{c}E=\lambda \cdot G \\
\left(f_{s}=0,667\right)\end{array}$ & $\begin{array}{c}E=\lambda \cdot G \\
\left(f_{s}=0,833\right)\end{array}$ \\
\hline$\lambda$ & 43 & 35 & 34 \\
\cline { 2 - 4 } & \multicolumn{3}{c}{ Pinus elliottii } \\
\cline { 2 - 4 } & $E=\lambda \cdot G$ & $E=\lambda \cdot G$ & $E=\lambda \cdot G$ \\
& $\left(f_{s}=0,667\right)$ & $\left(f_{s}=0,822\right)$ & $\left(f_{s}=0,833\right)$ \\
\hline$\lambda$ & 38 & 31 & 30 \\
\hline
\end{tabular}

Table 3 shows the results of the $\lambda$ coefficients obtained by the least square method of the relationship between the shear and longitudinal modulus of elasticity of the wood species investigated.

The results of the average values of the coefficients between the longitudinal and shear modulus of elasticity for Manilkara spp and Pinus elliottii timber beams were respectively equal to 37 and 33 , showing be $85 \%$ and $65 \%$ greater than the coefficient established between the modulus of elasticity by Brazilian standard ABNT 7190[3], implying shear modulus of elasticity 46 and 39\% lower than shown by the this standard.

The ratio between the longitudinal and shear modulus of elasticity found in this work for the Pinus elliottii (33) wood were $76.47 \%$ higher than the correlation coefficient between modules of Pinus elliottii (18.70) wood obtained from the work of Christoforo et al.[19], justified by the anisotropy of wood, local extraction of woods among others.

\section{Conclusions}

The results of the longitudinal and shear modulus of elasticity to the wood species investigated proved to be independent the choice of the form coefficients of cross section, being equivalent in both cases.

The average values of the coefficients of the relationship between the modulus of elasticity for the wood species were significantly different (higher) than the value set by the Brazilian standard[3], being the least of them, arising from Pinus elliottii wood, but still $65 \%$ higher, providing values of shear modules below the Brazilian standard.

For the anisotropy of wood combined with physical and chemical factors, the obtained results should not be extrapolated to the same or different woods species, thereby justifying the use of this calculation method developed in each study.

\section{REFERENCES}

[1] Christoforo, A. L.; Rocco, F. A. L; Morales, E. A. M.; Zangiácomo, A. L.; Panzera, T. H. Influence of Displacements on Calculus of the Longitudinal Modulus of Elasticity of Pinus Caribaea Structural Round Timber Beams. International Journal of Agriculture and Forestry, v. 2, p. 157-160, 2012.

[2] Christoforo, A. L.; Panzera, T. H.; Batista, F. B.; Borges, P. H.; Rocco, F. A. L. Numerical evaluation of the longitudinal modulus of elasticity in structural round timber elements of Eucalyptus genus. Revista Engenharia Agrícola, v. 31, p. 1007-1014, 2011.

[3] Associação Brasileira de Normas Técnicas (ABNT). NBR 7190. Projeto de Estruturas de Madeira. Rio de Janeiro, 1997.

[4] Pigozzo, J. C.; Pletz, E.; Lahr, F. A. R. Aspectos da classificação mecânica de peças estruturais de madeira. Anais In: VII Encontro Brasileiro em Madeiras e em Estruturas de Madeira, São Carlos, SP, 2000.

[5] Fiorelli, J.; Dias, A. A.; Coiado, B. Propriedades mecânicas 
de peças com dimensões estruturais de Pinus spp: correlação entre resistência à tração e classificação visual. Revista Árvore (Impresso), p. 741-750, 2009.

[6] Miotto, J. L.; Dias, A. A. Produção e avaliação de vigas de madeira laminada colada confeccionadas com lâminas de Eucalipto. Revista Tecnológica, Edição Especial ENTECA, p. 35-45, 2009.

[7] Ross. R. J.; Brashaw, B. K.; Pellerin, R. F. Nondestructive evaluation of wood. Forest Products Journal, v. 48, n. 1, p. 14-19, 1998.

[8] Erikson, R. G.; Gorman, T. M.; Green, D. W.; Graham, D. Mechanical grading of lumber sawn from small-diameter lodgepole pine, ponderosa pine, and grand fir trees from northern Idaho. Forest Products Journal, v. 50, n.7-8, p. 59-65, 2000 .

[9] Oliveira, F. G. R.; Sales, A. Ultrassonic measurements in Brazilian hardwood. Materials Research, v. 5, n. 1, p. 51-55, 2002.

[10] Miná, A. J. S.; Oliveira, F. G. R.; Calil Jr., C.; Dias, A. A.; Sales, A. Avaliação não destrutiva de postes de madeira por meio de ultrassom. Scientia Forestalis, n.65, p. 188-196, 2004.

[11] Wang, S. Y.; Chen, J. H.; Tsai, M. J.; Lin, C. J.; Yang, T. H. Grading of softwood lumber using non-destructive techniques. Journal of Materials Processing Technology, v. 208, p. 149-158, 2008.

[12] Liang, S.; Fu, F. Comparative study on three dynamic modulus of elasticity and static modulus of elasticity for Lodgepole pine lumber. Journal of Forestry Research, v. 18, p. 309-312, 2007.

[13] Dong, X. H.; Hai, W. L. Comparative study on four different methods for measuring the dynamic modulus of elasticity of Acer mono wood. Advanced Materials Research, v. 160-162, p. 384-388, 2011.

[14] Sales, A.; Candian, M.; Cardin, V. S. Evaluation of the mechanical properties of Brazilian lumber (Goupia glabra) by nondestructive techniques. Construction and Building Materials, v. 25, n. 3, p. 1450-1454, 2011.

[15] Rocco Lahr, F. A. Sobre a determinação de propriedades de elasticidade da madeira. Tese de Doutorado, 216 p., Engenharia de Estruturas. Escola de Engenharia de São Carlos, Universidade de São Paulo, São Carlos, 1983.
[16] Burdzik, W. M. G.; Nkwera, P. D. Transverse vibration tests for prediction of stiffness and strength properties of full size Eucalyptus grandis. Forest Products Journal, v. 52, n. 6, p. 63-67, 2002.

[17] Zangiácomo. A. L; Rocco Lahr, F. A. Avaliação do efeito do cisalhamento na flexão de elementos roliços da espécie Eucalyptus Citriodora. Anais In: XI Encontro Brasileiro em Madeiras e em Estruturas de Madeira, Londrina-PR, 2008.

[18] Christoforo, André Luis; Icimoto, F. H.; Fernandes, C. V.; Fiorelli, J.; Negrao, J.; Rocco, F. A. L. Shear and Longitudinal Modulus of Elasticity in Structural Profiled Round Timber Beams. International Journal of Materials Engineering, v. 3, p. 87-91, 2013.

[19] Christoforo, A. L.; Ribeiro Filho, S. L. M.; Panzera, T. H.; Rocco, F. A. L. Metodologia para o cálculo dos módulos de elasticidade longitudinal e transversal em vigas de madeira de dimensões estruturais. Ciência Rural (UFSM. Impresso), v. 43, p. 610-615, 2013.

[20] American Society for Testing and Materials (ASTM). Standard test method of static tests of lumber in structural sizes. ASTM D-198. Annual book of ASTM standards, v. 03.01. ASTM, West Conshohocken, Philadelphia, 1997.

[21] Sanches Jr., F.; Venturini, W. S. Damage modeling of reinforced concrete beams. Advances in Engineering Software, v. 38, n. 8-9, p. 538-546, 2006.

[22] Timoshenko, S. P. Strength of materials - Part 1. Second edition, D. Van Nostrand Company, Inc., New York, pp. 170-171, 1940.

[23] Mindlin, R. D.; Deresiewicz, H. Timoshenko's shear coefficient for flexural vibration of beams. Technical Report, $\mathrm{n}^{\mathrm{o}} .10$, ONR Project NR064-388, Department of Civil Engineering, Columbia University. New York, 1953.

[24] Roark, R. J. Formula for stress and strain. Third edition, McGraw-Hill Book Company, Inc, New York, pp. 119-121, 1954.

[25] Christoforo, A. L.; Rocco, F. A. L.; Morales, E. A. M.; Panzera, T. H.; Borges, P. H. Numerical Evaluation of Longitudinal Modulus of Elasticity of Eucalyptus grandis Timber Beams. International Journal of Agriculture and Forestry, v. 2, p. 166-170, 2012. 